\title{
DIAGNÓSTICO DOS EFEITOS DA PANDEMIA DE COVID-19 NA GESTÃO DO CURSO DE ENGENHARIA CIVIL DA UFC E PROPOSIÇÃO DE PAINEL DE CONTINUIDADE DO ENSINO
}

Cely M. S. de Alencar - celyms@ufc.br

Mateus F. P.da Silva - mateuspeixoto@alu.ufc.br

Curso de Engenharia Civil - Universidade Federal do Ceará

Campus do Pici, Bloco 708

60020-181 - Fortaleza - Ceará

Resumo: O advento da pandemia do novo coronavírus (COVID-19) no Ceará, durante o início do ano de 2020, causou diversos transtornos em vários ambientes. Durante a realização deste estudo, o estado ocupava a terceira posição no ranqueamento nacional de casos, devido aos crescentes índices de forma preventiva a Universidade Federal do Ceará deliberou a suspensão das atividades presenciais na Universidade Federal do Ceará. Neste contexto, o curso de Engenharia Civil possui a integralidade de suas disciplinas ministradas presencialmente, notável participação de atividades de laboratório e, mesmo estando em processo de reforma curricular, ainda percebe-se a ausência de método de diagnóstico para a proposição de ações emergenciais. Desse modo, o Centro Acadêmico de Engenharia Civil associado com a Coordenação de Curso propõe este modelo de análise situacional que contemplam percepções docentes, discentes, de gestão acadêmica e dos aparatos tecnológicos da instituição e dos alunos.

Palavras-chave: Pandemia. Gestão. Diagnóstico.

\section{INTRODUÇÃO}

O Plano Pedagógico de Curso (PPC) é o documento regimental das ações de gerência, organização curricular e perfil de egresso da graduação. A diretriz acadêmica está sustentada em princípios relacionados à interdisciplinaridade, integração de atividades teóricas-práticas e a reação entre ensino, pesquisa e extensão. Deste modo, é buscada uma formação de atualização constante e construída a partir de diversos meios de aprendizagem, enfatizando a associação entre ciência, tecnologia e ética. A estrutura curricular é constituída de 3600 horas, a Tabela 1 mostra como é dividida a carga horária que é planejada para ser concluído em dez semestres letivos.

Tabela 1 - Descrição de carga horária.

\begin{tabular}{|c|c|}
\hline Descrição & Horas \\
\hline Carga Horária Teórica Obrigatória & 2640 \\
\hline Carga Horária Prática Obrigatória & 368 \\
\hline Carga Horária Optativa Mínima & 592 \\
\hline
\end{tabular}

Fonte: PPC Engenharia Civil UFC (2004). 
É perceptível que não há a previsão de atividades na modalidade de ensino à distância (EaD), a maioria das aulas teóricas são ministradas a partir de notas escritas ou expostas em multimídia, leitura de bibliografia e análise/discussão de situações cotidianas ao engenheiro. A modalidade prática de ensino está presente nos ciclos básico e profissional, não somente com as atividades laboratoriais, mas também com trabalhos de campo e atividades de estudo de caso. Um exemplo de integração teórico-prática neste curso é tratada no trabalho "Interdisciplinaridade entre componentes curriculares do Departamento de Engenharia de Transportes por meio da Aprendizagem Baseada em Projetos" (SILVA, M. F. P. et al, 2019) em que discute-se um método de ensino que se relacionam conhecimentos técnicos de três disciplinas, aprendizagem baseada em projetos e problemas e a instrução pelos colegas.

Neste contexto, o Núcleo Docente Estruturante (NDE), composto pela gestão acadêmica e professores, com observação da representação discente liderada pelo Centro Acadêmico de Engenharia Civil (CAEC), é responsável por apreciar mudanças no PPC. O órgão deliberativo máximo do curso é o Colegiado de Curso, composto pelos mesmos entes do NDE, que junto aos departamentos fornecedores de disciplinas orientam as ações de ensino. Dessa maneira, é perceptível a crescente implementação e aceitação das metodologias ativas de aprendizagem, o que demanda aparato técnico e treinamento para o melhor aproveitamento. Destarte, é inteligível que o curso passa por uma fase de transição de formação meramente conteudista para o aprendizado por competências.

O PPC mostra-se um documento detalhado de execução das ofertas de disciplinas e aliado ao Calendário Universitário causa um padrão de disponibilização dos componentes curriculares. O qual não passa por muitas alterações desde 2017, com a amarração de alguns tópicos em determinado semestre letivo. A oferta para o primeiro semestre de 2020 foi planejada desde outubro do ano anterior, a alocação de professores, horários e salas de aula é feita com a participação de todos os entes participantes do curso; a publicação do padrão disciplinar é feita com antecedência no Sistema Integrado de Gestão de Atividades Acadêmicas (SIGAA) para o planejamento dos matriculáveis.

Neste ínterim, enquanto ocorria o início das aulas em meados de fevereiro de 2020, a conjuntura internacional já apontava os efeitos políticos, sociais e econômicos que a disseminação do novo coronavírus causava na Ásia e Europa. Entretanto, no mês seguinte, a pandemia já afetava o cotidiano local, o que ocasionou a suspensão das atividades presenciais em todos os campi da Universidade Federal do Ceará em 16 de março de 2020. O provimento encaminhado pela Reitoria ao Conselho Universitário (CONSUNI) orienta que as atividades acadêmicas devem prosseguir de forma remota, mas sem estabelecer um padrão de viabilidade, realização, acompanhamento e avaliação de funcionalidade. Além disso, a falta de definição e detalhamento nas orientações causou em momento inicial o conflito entre diretrizes adotadas inicialmente por instâncias inferiores de administração.

As práticas remotas de ensino como uma substituição ao modelo corrente de aula presencial foram adotadas de forma autônoma pelos docentes e não estavam sendo acompanhadas pela integralidade do corpo discente, o qual em diversas vezes, a maioria manifestou ser contra os métodos de ensino online. Os órgãos de gestão internos nos níveis departamental e de curso não conseguem orientar com clareza seus professores quanto a realização das atividades, visto que não há protocolo precedente de ações e nem diagnóstico que contemplasse as várias perspectivas relacionadas à situação. 


\section{OBJETIVOS}

São objetivos gerais compreender como a estrutura docente, discente e técnica do curso de Engenharia Civil da UFC reagem e/ou se adaptam a imposição de quarentena sanitária em que o espaço físico da Universidade tem o acesso impedido. Além de compreender a problemática gerada pela ocorrência das atividades remotas e propor ações mitigadoras e de restauração ao cotidiano acadêmico. Estas informações compõem o Painel de Continuidade do Ensino. Ademais, no contexto da transição curricular, a situação mostra-se como uma oportunidade de avaliar como os métodos de ensino online podem ou não se encaixar como suporte aos componentes curriculares plenamente presenciais.

Destacam-se como objetivos específicos: obter um painel de inclusão digital do corpo discente; observar a adaptação docente a novos métodos de ensino, no contexto da turma virtual compulsória e gerar um escopo de atividades aplicáveis e monitoráveis.

\section{MÉTODO}

O estudo foi realizado com foco predominante na investigação de percepções dos entes componentes do curso de Engenharia Civil. Inicialmente, a fase de avaliação de viabilidade da aplicação dos métodos remotos de ensino foi realizada com o questionário proposto pela administração do Centro de Tecnologia, que congrega os 14 cursos de engenharia existentes no Campus do Pici. Em seguida, o Centro Acadêmico de Engenharia Civil fez a captação de percepções dos alunos matriculados acerca da situação corrente, a qual apresenta variedade de cenários. A seguir, o questionário aplicado aos alunos foi adaptado pela Coordenação de Curso e distribuído aos professores ministrantes da oferta do primeiro semestre de 2020 . Posteriormente, a mescla das informações colhidas e tratadas gera o Painel de Continuidade e passa a ser possível compreender os efeitos da suspensão de atividades presenciais.

\subsection{Avaliação Preliminar de Viabilidade}

A pesquisa sobre uso de dispositivos e acesso à Internet foi realizada a partir do dia 14 de março de 2020 pela Diretoria do Centro de Tecnologia, além de questionar docentes, técnicos e discentes acerca da suspensão de atividades presenciais. Também consistiu em um levantamento de componentes curriculares ofertados para as engenharias, sendo a Engenharia Civil líder com 111 turmas do referido centro, correspondente à 19\% das turmas.

O acompanhamento das ações remotas pela Diretoria foi realizada entre os dias 24 e 27 de abril de 2020, por meio de formulário eletrônico dirigido aos discentes e docentes. Estas perguntas trataram acerca de: a) quantidade de turmas de estão com atividades remotas; b) plataforma de comunicação com a turma; c) percepções acerca da obrigatoriedade, motivação e alcance das atividades propostas; d) potenciais dificuldades na aplicação dos métodos. Este último item será o mais importante para a compreensão da situação das engenharias, os itens anteriores são contemplados com os questionários propostos apenas na Engenharia Civil.

\subsection{Captação de Percepções Discentes}

O CAEC realizou a pesquisa com os alunos para a avaliação de aceitação das atividades remotas entre os dias 4 e 8 de abril de 2020. O levantamento foi realizado por meio de formulário eletrônico, amplamente divulgado nas mídias sociais da instituição e SIGAA. Esta apuração foi dividida em dois blocos de perguntas, além da identificação da turma e docente ministrante, os alunos responderam o formulário de forma totalmente anônima. 
O primeiro bloco de questões é a descrição das atividades que estavam sendo propostas ou desenvolvidas pelo professor para aquele componente curricular. Foram idealizadas onze atividades-padrão, a opção nula e a opção aberta. São as propostas de: a) utilização de fórum de discussões; b) disponibilização de e-mail ou contato telefônico docente; c) realização de transmissões de aulas remotas com e sem anotação de frequência; d) disponibilização de listas de exercícios com e sem entrega obrigatória; e) cobrança de envio de atividades propostas anteriores à suspensão presencial; f) envio de conteúdos de leitura ou audiovisuais para estudo; g) proposição de trabalhos avaliativos com e sem entrega obrigatória; e) proposição de avaliações progressivas por meio eletrônico.

A parte seguinte trata da avaliação das atividades propostas na turma e percepção sobre o Método de Ensino Online (MEO), os respondentes devem atribuir conceitos de aproximação com sua percepção às seguintes questões: a) eficácia do método comparada às aulas presenciais; b) preservação da equidade de acesso ao ensino; c) dispensa de reposição parcial ou integral das atividades presenciais; d) promoção de aprendizagem compartilhada e mútua. Neste contexto, a análise destes dados gera um dashboard por componente curricular, docente, atividades propostas e avaliação conforme respostas obtidas. Para este levantamento, foram recebidas 374 respostas, sendo que foram registrados 609 alunos matriculados para o semestre 2020.1, o que representa um índice de respostas por aluno em 0,6.

\subsection{Captação de Percepções Docentes}

O formulário para o preenchimento dos professores que compõem os departamentos que fornecem disciplinas ao curso de Engenharia Civil foi disponibilizado entre os dias 22 de abril e 14 de maio. Sua divulgação foi impulsionada pela Coordenação de Curso e recebeu 51 respostas para os 54 componentes curriculares selecionados para a pesquisa. $O$ percentual de resposta docente foi de $68 \%$ - 38 docentes para o total de 56. Isto decorre devido a componentes curriculares apresentarem mais de um professor ministrante e, docentes ministrarem várias turmas, sendo que foi proposto para o professor responder para cada componente em separado. Desse modo, o questionário proposto para os docentes é a adaptação do que foi proposto para alunos, isto, pois, foi necessário para que se obtenham noções diferentes, mas não necessariamente antagônicas sobre as mesmas questões. Foi incluído um bloco adicional, com questões acerca da perspectiva da retomada de ensino. Neste contexto, os docentes foram instigados a responder acerca de: a) oferta corrente; b) oferta de semestre seguinte; c) situação de alunos que não puderam acompanhar o MEO; d) conclusão da disciplina para os alunos que concluírem o MEO; e) necessidade de elaboração de um protocolo de retomada para o curso.

O tratamento e análise destes dados segue um método similar ao de captação das percepções discentes. Entretanto, com um cuidado maior para o direcionamento correto das atividades do componente curricular para a solvência de possíveis situações incômodas para qualquer ente do curso.

\subsection{Painel de Continuidade e Diagnóstico Situacional}

O levantamento das atividades propostas e suas respostas de alunos e professores permitem avaliar como cada docente trata a sua disciplina e verificar avaliações de ambos acerca do método online aplicado em cada disciplina. Estas avaliações permitem conhecer os tipos de atividade, meios empregados, regularidade da ocorrência e tendência à padronização por disciplina ou departamento. As atividades propostas foram marcadas de forma cromática que destacam a sua importância e/ou impacto para os entes do componente curricular.

Alguma atividade ou situação é declarada como significativa a partir da quantidade de respostas, para o formulário discente são, no mínimo, duas citações. Foram divulgados em 
meios oficiais apenas os resultados estatísticos e sem exposição de componente curricular ou docente. Para o formulário docente, aplica-se o método similar ao formulário discente, o diagnóstico da ocorrência de situação é com a resposta absoluta do professor ao preencher o questionário.

Destarte, foi montada uma árvore de problemas com as avaliações e percepções estimuladas pelas perguntas e que os entes sugeriram em espaço apropriado no questionário. A representação busca relacionar as situações percebidas pelos entes acadêmicos e a natureza delas. Além das perspectivas para a retomada de ensino, compondo o prognóstico. Será o ponto de partida para a adoção de medidas que abrangem o curso, as questões referentes aos componentes curriculares em si, são tratados e mediados imediatamente pela Coordenação de Curso e a representação discente. A rede de problemas está separada por percepções discentes, docentes e de ambos; outra forma de classificação é por ramos: a) diagnóstico da situação atual; b) perspectivas/prognóstico; c) intervenção.

\section{RESULTADOS}

Os resultados para o levantamento realizado pela Diretoria do CT apontam que em que mais de $82 \%$ dos respondentes (196 docentes; 40 técnicos administrativos; 1.895 discentes) indicou que as aulas presenciais deveriam ser suspensas. $48 \%$ dos respondentes disseram ser favoráveis ao uso de metodologias de ensino remotas. A Tabela 2 traz a compilação das percepções frente às dificuldades encontradas por discentes e docentes com mais de $50 \%$ de ocorrências. A pesquisa de acompanhamento indicou que para o curso de Engenharia Civil foram registradas em torno de 20 respostas docentes e 110 respostas discentes.

Tabela 2: Potenciais dificuldades apontadas por discentes e docentes.

\begin{tabular}{|c|c|}
\hline Discentes & Docentes \\
\hline Internet & Internet \\
\hline Esclarecimento de dúvidas & Estudantes sem computador \\
\hline Concentração & Organização familiar \\
\hline Ambiente inapropriado & Ambiente inapropriado \\
\hline Equipamento & Transição presencial para o EaD \\
\hline Apresentação de slides & Conteúdo \\
\hline Atividades desconexas & Tempo \\
\hline Atividades de laboratório & Medo de angústia \\
\hline Qualidade do Som/Áudio & Concentração \\
\hline Vídeos longos & Alunos desanimados \\
\hline
\end{tabular}

Fonte: Autores

Neste contexto, para o formulário discente proposto pelo CAEC, com 374 respostas foi possível caracterizar as 54 disciplinas propostas para a consulta, a Tabela 3 mostra quantas respostas foram cadastradas para os dez componentes curriculares com maior frequência de preenchimento pelos discentes, acompanhado do período regular de oferta mostrado em índices absoluto e percentual sobre total de respostas.

Tabela 3: Dez maiores ocorrências de respostas do formulário discente.

\begin{tabular}{|c|c|c|c|}
\hline Componente Curricular & Período & Respostas & $\%$ \\
\hline Desenho para Engenharia & 1 & 57 & $15,2 \%$ \\
\hline Análise e Planejamento do Sistema de Transportes & 5 & 24 & $6,4 \%$ \\
\hline Projeto e Construção de Edifícios I & 5 & 21 & $5,6 \%$ \\
\hline
\end{tabular}


(C) COBENGE

"Os desafios para formar hoje o engenheiro do amanhã"
$\mathrm{Ol}$ a $\mathrm{O3}$ de dezembro

Evento On-line

\begin{tabular}{|c|c|c|c|}
\hline Materiais de Construção Civil I & 3 & 17 & $4,5 \%$ \\
\hline Mecânica dos Fluidos & 5 & 15 & $4,0 \%$ \\
\hline Engenharia Econômica & 5 & 14 & $3,7 \%$ \\
\hline Fundamentos da Economia & 3 & 13 & $3,5 \%$ \\
\hline Análise de Estruturas I & 7 & 12 & $3,2 \%$ \\
\hline Topografia & 3 & 12 & $3,2 \%$ \\
\hline Mecânica dos Solos I & 5 & 11 & $2,9 \%$ \\
\hline
\end{tabular}

Fonte: Autores

A Figura 1 mostra o infográfico de percentuais de ocorrência de onze propostas que foram assinaladas pelos discentes e a opção de não proposição do Método de Ensino Online, separadas cromaticamente pela importância ou impacto gerado. São dados que consideram todos os componentes curriculares, sendo que em relatório enviado a gestão do curso está a situação detalhada por disciplina e docente. Estes índices contribuirão para as ações da Coordenação e solvência de possíveis conflitos de aprendizagem.

Figura 1: Frequência de atividades propostas apontada pelos discentes.

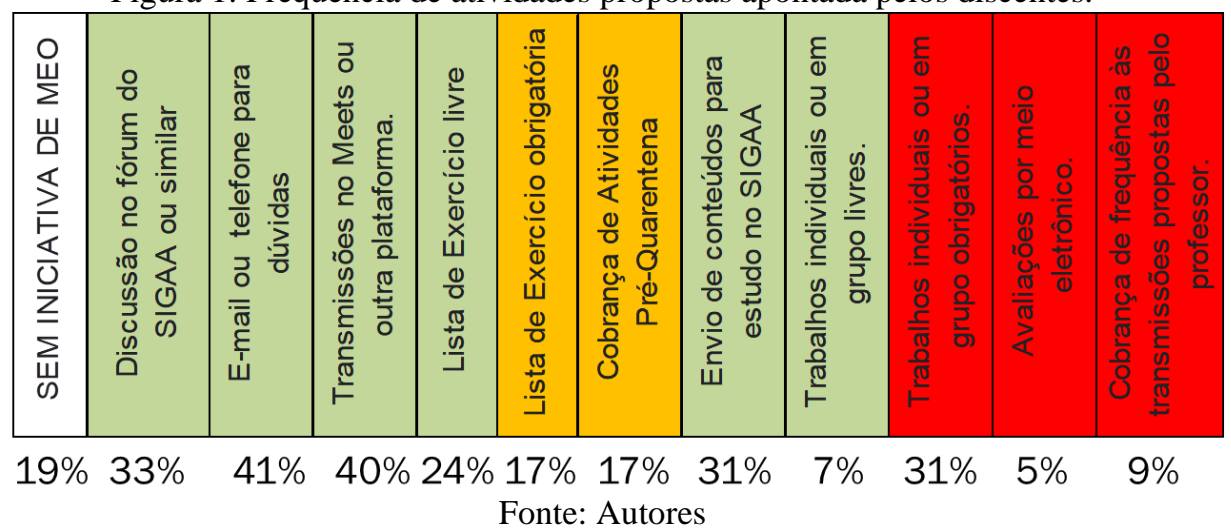

O gradiente cromático exposto na Figura 2, mostra de forma cromática qual o nível de concordância (tendência ao verde) ou discordância (tendência ao vermelho) sobre as quatro questões acerca da avaliação do MEO em quatro níveis.

Figura 2: Avaliação do Método de Ensino Online.

Eficácia do MEO em substituir as aulas presenciais.

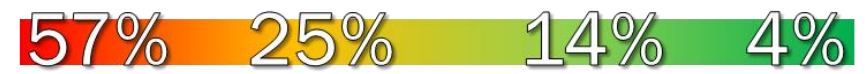

Equidade de acesso dos alunos ao MEO.

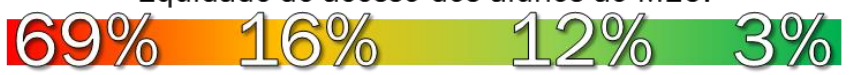

Dispensa de reposição das atividades presenciais.

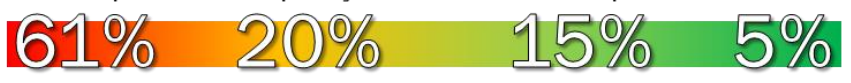

Aprendizagem compartilhada, mútua e coletiva no MEO.

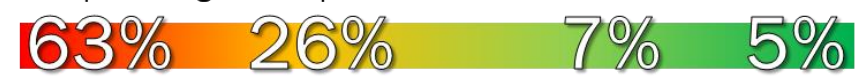

Fonte: Autores

Neste ínterim, na Figura 3, está o infográfico acerca das atividades propostas apontadas pelos professores em formulário interno do curso de Engenharia Civil, estas são respostas 
(C) COBENGE

"Os desafios para formar hoje o engenheiro do amanhã"
O1 a 03 de dezembro Evento On-line

para os 38 docentes que responderam até o dia 14 de maio de 2020. Já a Tabela 4, mostra a comparação entre as frequências de apontamento de tarefas pelos alunos e professores e o desvio em pontos percentuais.

Figura 3: Frequência de atividades propostas apontada pelos docentes.

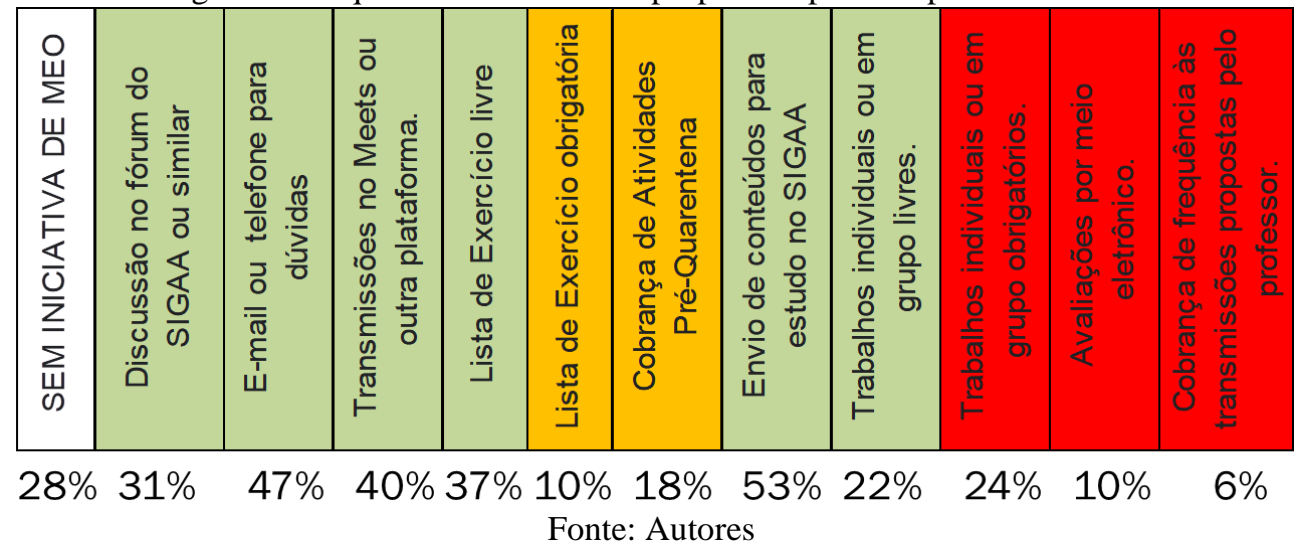

Tabela 4: Comparação entre frequência de apontamento das atividades.

\begin{tabular}{|c|c|c|c|}
\hline Atividades & $\begin{array}{c}\text { Discente } \\
(\%)\end{array}$ & $\begin{array}{c}\text { Docente } \\
(\%)\end{array}$ & $\begin{array}{c}\text { Desvio } \\
(\text { p.p. })\end{array}$ \\
\hline SEM INICIATIVA DE MEO & 19 & 28 & 9 \\
\hline Discussão no fórum do SIGAA ou similar & 33 & 31 & 2 \\
\hline E-mail ou telefone para dúvidas & 41 & 47 & 6 \\
\hline Transmissões no Meets ou outra plataforma. & 40 & 40 & 0 \\
\hline Lista de Exercício livre & 24 & 37 & 13 \\
\hline Lista de Exercício obrigatória & 17 & 10 & 7 \\
\hline Cobrança de Atividades Pré-Quarentena & 17 & 18 & 1 \\
\hline Envio de conteúdos para estudo no SIGAA & 31 & 53 & 18 \\
\hline Trabalhos individuais ou em grupo livres. & 7 & 22 & 15 \\
\hline $\begin{array}{c}\text { Trabalhos individuais ou em grupo } \\
\text { obrigatórios. }\end{array}$ & 31 & 24 & 7 \\
\hline Avaliações por meio eletrônico. & 5 & 10 & 5 \\
\hline $\begin{array}{c}\text { Cobrança de frequência às transmissões } \\
\text { propostas pelo professor. }\end{array}$ & 9 & 6 & 3 \\
\hline
\end{tabular}

Fonte: Autores

A Figura 4 traz as avaliações docentes quanto ao Método de Ensino Online, apenas qualificando em positivo ou negativo para concordância, adequação ou pertinência da assertiva com as ações adotadas junto com as respostas para a perspectiva de retomada e continuidade do ensino (Figura 5). 


\section{G COBENGE (C) COBENCE 2020 e III Simpósio Internacional de Educação em Engenharia da ABENGE}

\section{"Os desafios para formar hoje o engenheiro do amanhã"}

Figura 4: Avaliações docentes da situação atual de aplicação do MEO.

O MEO é a melhor solução para a conjuntura.

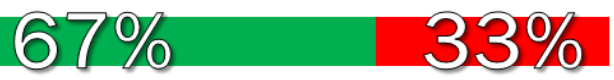

Equidade de acesso dos alunos ao MEO.

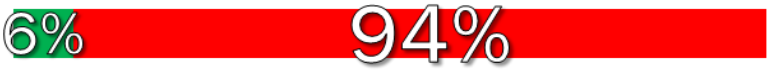

Dispensa de reposição das atividades presenciais.

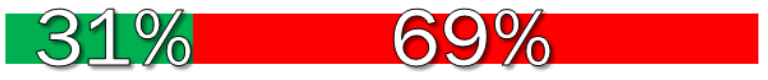

Aprendizagem compartilhada, mútua e coletiva no MEO.

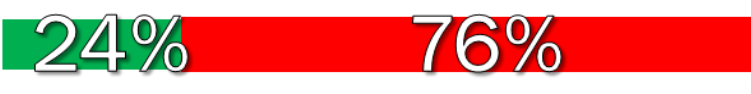

Fonte: Autores

Figura 5: Perspectivas docentes para retomada do ensino presencial.

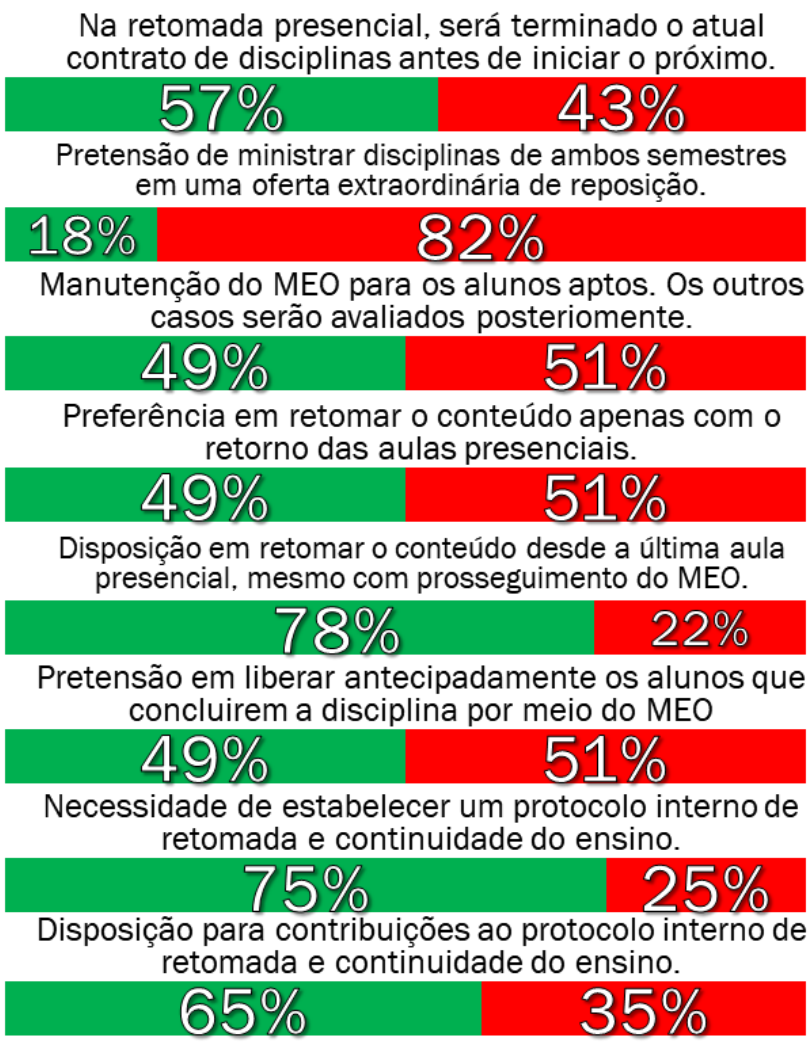

Fonte: Autores

Diante dos resultados expostos e das indicações enviadas no espaço aberto de ambos os formulários, foi possível compor a problemática. A árvore indicando as situações e hipóteses de causalidade são retratadas pela Figura 6. 
Figura 6: Problemática para o curso de Engenharia Civil da UFC no primeiro semestre de 2020.

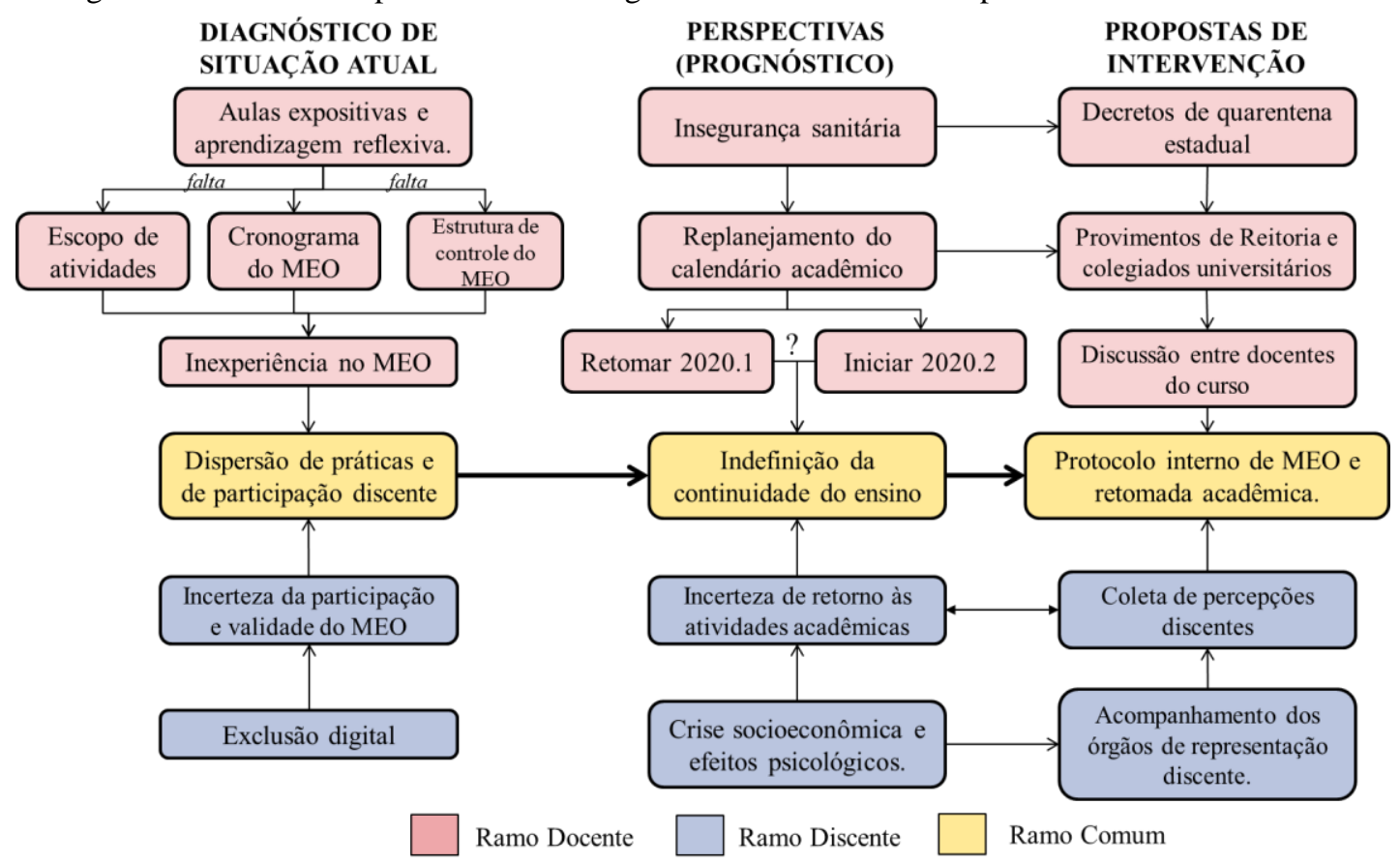

\section{CONCLUSÕES}

Fonte: Autores

Destarte, é possível considerar a partir das percepções apontadas pelos discentes e docentes em formulário proposto pela Diretoria que não ocorre uniformidade de ações remotas, baixa adesão por parte dos estudantes, desmotivação por parte discente, discrepâncias em termos de cobrança de atividades, frente ao conteúdo.

Seguindo a perspectiva discente interna, foi possível compreender a situação de acesso as tecnologias inerentes à formação do engenheiro e percebe-se a importância que os recursos técnicos da Universidade exerce na promoção da igualdade digital, sobretudo para estudantes de baixa renda. Justamente, a impossibilidade de acesso a estes aparelhos causa a disparidade de comparecimento discente a muitas atividades remotas. Logo, para a implementação de métodos digitais na Universidade, é necessário primeiro assegurar que esta tenha os equipamentos necessários para garantir a participação dos discentes e a plena qualidade da formação.

Em uma perspectiva curricular e docente internas, é notório que o MEO é mais aplicado nas disciplinas de ciclo profissional (a partir do $5^{\circ}$ período acadêmico). Isto, pois, todos os componentes são semestrais. Apesar disso, as respostas para uma disciplina de início de curso, Desenho para Engenharia, figura com maior número de respostas. Isto se deve a grande dependência que a disciplina tem do Laboratório de Modelagem da Informação (LMI), o qual possui computadores com recursos necessários para o andamento da disciplina.

Além disso, as onze atividades propostas tem frequências de ocorrências apontadas muito próximas por discentes e docentes, o que denota a complementação das percepções discentes e docentes quanto à clareza das atividades correntes. Entretanto, torna-se perceptível também a discrepância de ações, meios, propostas, visto que a frequência de respostas varia entre as atividades. Há um percentual significativo de respostas para disciplinas que não estão tendo proposta de MEO. Ocorre um fenômeno de convergência docente para a necessidade de elaborar um protocolo interno de continuidade e de retomada de atividades acadêmicas presenciais, mesmo que temporário ou aplicável posteriormente, mas também não conflitante com instâncias superiores. 
Diante disso, percebe-se que as pesquisas realizadas pela Diretoria, Coordenação e representação discente são complementares, pois tratam acerca do levantamento das dificuldades e de atividades propostas para a retomada do ensino, respectivamente. As potenciais dificuldades estão sustentadas no rastreio das percepções discentes, visto que devido às respostas serem anônimas, não podendo associar os alunos às suas turmas, também a elaboração de protocolo de retomada ser organizada de modo que cada docente possa aplicar às contingências das turmas. Pode-se afirmar que o método proposto consegue contemplar a compreensão de situação microscópica, no âmbito do modo como os docentes estão tratando a continuidade do ensino em seus componentes curriculares. Mas também, em situação macroscópica, fornecendo um painel situacional e de tendências, utilizado para direcionar ações de órgãos gestores. A sugestão de continuidade para este estudo é a aplicação do método proposto e a avaliação de seus resultados.

\title{
REFERÊNCIAS
}

Estrutura curricular do curso de Engenharia Civil. Disponível em: https://si3.ufc.br/sigaa/public/curso/curriculo.jsf?lc=pt_BR\&id=657474. Acesso em: 25 abril 2020.

Projeto Pedagógico do Curso de Engenharia Civil da UFC, 2004. Disponível em: http://www.si3.ufc.br/sigaa/public/curso/ppp.jsf?lc=pt_BR\&id=657474. Acesso em: 25 abril 2020.

Relatório sobre atividades remotas. Centro de Tecnologia UFC, 2020.

SILVA, Mateus F. P. et al. Interdisciplinaridade entre componentes curriculares do Departamento de Engenharia de Transportes por meio da Aprendizagem Baseada em Projetos. In: XLVII Congresso Brasileiro de Educação em Engenharia, 2019, Fortaleza. Anais.

\section{DIAGNOSIS OF THE EFFECTS OF THE COVID-19 PANDEMIC ON THE MANAGEMENT OF THE UFC'S CIVIL ENGINEERING COURSE AND THE PROPOSITION OF THE TEACHING CONTINUITY PANEL}

\begin{abstract}
The advent of the new coronavirus pandemic (COVID-19) in Ceará, during the beginning of 2020, caused several disorders in various environments. During the conduct of this study, the state ranked third in the national ranking of cases, this required the decree to suspend presentially activities at the Federal University of Ceará. In this context, the Civil Engineering course has all of its subjects taught in person, a notable participation in laboratory activities and, even though it is in the process of curriculum reform, there is still a lack of diagnostic method for proposing emergency actions. In this way, the Academic Center for Civil Engineering associated with the Course Coordination proposes this model of situational analysis that includes perceptions of teachers, students, academic management and technological apparatus of the institution and students.
\end{abstract}

Keywords: Pandemy. Management. Diagnostic. 